\title{
Management of the Palatal Donor Area after Harvesting a Connective Tissue Graft: A Case Series

\author{
João Carnio, DDS, $M^{1^{*}}$ and Anna Tereza Carnio ${ }^{2}$
}

${ }^{1}$ Private Practice, Londrina, Brazil

${ }^{2}$ DDS Student, University of North Parana, Brazil

*Corresponding author: João Carnio, DDS, MS, Private Practice, Avenida Adhemar Pereira de Barros 131, Jardim Bela Suica 86050-190, Londrina, Parana, Brazil, Tel: +55-43-999098484

\begin{abstract}
Purpose: The manipulation of the palatal flap after harvesting a connective tissue graft (CTG) plays an important role when the palatal donor area is intended to be used more than once. The palatal flap can be handled in one of two ways. One option is the coaptation of the borders, to facilitate healing by the first intention. The second option is the compression of the palatal flap against the bone, which is allowed to heal by secondary intention.

Methods: Sixteen non-smoking patients who participated in the current study were divided into two groups based on the bleeding time after CTG removal. When the bleeding stopped within 1.5 minutes or less, the primary closure procedure was used (Group 2). When the bleeding persisted for more than 1.5 minutes, the palatal flap compression procedure was performed (Group 1).

Results: Six months later, Group 1 presented a decrease in palatal thickness compared with the baseline measurement. In contrast, Group 2 showed no significant difference in palatal thickness compared with the baseline. These results indicated that the first intention healing procedure should be the procedure of choice if the same palatal donor area is intended for more than one use.
\end{abstract}

\section{Introduction}

Since the introduction of the autogenous connective tissue graft (CTG) in the early 80 s, this procedure has been considered the gold standard technique for periodontal plastic surgery [1-3]. The predictability, longterm results, and the color matching of the tissues are advantages of this procedure, whereas the drawbacks include the limited availability of palatal donor tissue to treat multiple recessions and the bleeding of the donor area both during and post-operatively [4]. To overcome the lack of donor tissue availability, the same palatal donor area might be used more than once [5].

After the CTG has been harvested, the palatal flap can be treated in one of two ways. The first option is the coaptation of the borders to facilitate healing by the first intention [6]. The second option is the compression of the palatal flap against the bone, to quickly halt the bleeding, with the expectation of healing by secondary intention [7].

Most studies only describe the techniques used to remove the CTG and only discuss the outcomes in bleeding and the patient's post-operative discomfort [8]. To date, no studies have mentioned the healing of the palatal donor area, particularly the post-operative thickness (PT).

The aim of the present study was to compare the thickness of the postoperative palatal donor area after harvesting a CTG between the healing by the first intention, compared with healing by the secondary intention, and the consequences of PT on prospective treatment planning.

\section{Materials and Methods}

A total of 16 non-smoking patients participated in this retrospective study ( 12 female and 4 male). None of the patients reported any previous hemorrhagic episodes after trauma during surgery, spontaneous bleeding, or any family history of hereditary bleeding disorders. All study subjects were referred to private practice in

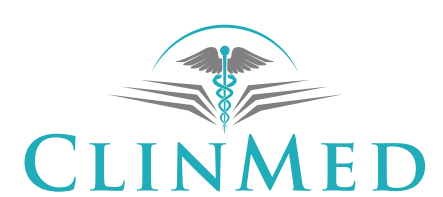

INTERNATIONAL LIBRARY
Citation: Carnio J, Carnio AT (2021) Management of the Palatal Donor Area after Harvesting a Connective Tissue Graft: A Case Series. Int J Oral Dent Health 7:130. doi.org/10.23937/2469-5734/1510130 Accepted: June 08, 2021: Published: June 10, 2021

Copyright: (C) 2021 Carnio J, et al. This is an open-access article distributed under the terms of the Creative Commons Attribution License, which permits unrestricted use, distribution, and reproduction in any medium, provided the original author and source are credited. 
Londrina-Parana, Brazil, for root coverage procedures. Oral consent was obtained for the collection and use of data, and the guidelines of the Helsinki Declaration were followed. The patients were divided into two groups, based on the bleeding time after CTG removal. When the bleeding stopped within 1.5 minutes or less, the primary closure procedure was used (Group 2). When the bleeding persisted for more than 1.5 minutes, the palatal flap compression procedure was performed (Group 1) [9].

Group 1 comprised 10 patients ( 7 female and 3 male), with a mean age of 44 years and an average of 2.83 teeth per site (range 2-4). Group 2 comprised 6 patients ( 5 female and 1 male), with a mean age of 40 years and an average of 3.20 teeth per site (range 2-4).

All donor areas were dentate, presented with palatal vaults, ranging between average to high, with a mean thickness of $3 \mathrm{~mm}$ at baseline. Probing depths, marginal tissue recession, and the palatal thickness was measured at baseline and 6 months after CTG removal, using a standard manual periodontal probe (PCP-UNC 15, HuFriedy). Under locally administered anesthesia, the palatal thickness was recorded using a probe inserted perpendicularly to the mucosal surface at the long axis of each tooth (mid-palatal surface), approximately 5 $\mathrm{mm}$ from the gingival margin, until it reached the bone. The pre- and post-treatment areas were measured to the nearest $0.5 \mathrm{~mm}$.

\section{Surgical procedures}

The one-incision surgical technique [6] was performed, from the canine to the mesial of the first molar, to obtain a $1.5-\mathrm{mm}$ graft thickness. At the end of the procedure, the palatal wound was treated as follows: For the first intention healing group (Group 2), a sling suture was used to join the borders of the wound, and then cyanoacrylate tissue glue was applied over the incision. For the compression sites [7], external pressure was applied to maintain the flap against the bone, until the bleeding stopped. Then, cyanoacrylate tissue glue was used to secure the flap position.

Both sutures and the cyanoacrylate tissue glue were removed after 1 week. All data were analyzed using the Wilcoxon signed-rank test.

\section{Results}

Healing proceeded uneventfully at the palatal donor areas for both groups. The results of the study are illustrated in Table 1. Treatment with palatal compression (Group 1) resulted in a significant decrease in palatal thickness compared with the baseline measurement. The average pre- and post-operative thicknesses were $2.73 \mathrm{~mm}$ and $2.12 \mathrm{~mm}$, respectively. In the primary closure procedure (Group 2), the results showed no significant difference in thickness compared with the baseline measurement. The average pre- and post-operative thicknesses were $2.92 \mathrm{~mm}$ and $3.06 \mathrm{~mm}$, respectively. The mean probing depth and recession did not differ significantly between the two groups.

\section{Discussion}

The palatal masticatory mucosa is the most suitable area to obtain autogenous donor tissue for the

Table 1: The results of the study.

\begin{tabular}{|c|c|c|c|c|}
\hline & Patients & Initial & Final & p-value \\
\hline \multicolumn{5}{|l|}{ PD } \\
\hline Group 1 & 10 & $1.79 \pm 0.47$ & $1.75 \pm 0.50$ & 0.92 n.s \\
\hline Group 2 & 6 & $1.91 \pm 0.39$ & $2.19 \pm 0.31$ & 0.07 n.s \\
\hline \multicolumn{5}{|l|}{ PT } \\
\hline Group 1 & 10 & $2.73 \pm 0.48$ & $2.12 \pm 0.31$ & $0.00^{*}$ \\
\hline Group 2 & 6 & $2.92 \pm 0.92$ & $3.06 \pm 0.76$ & 0.47 n.s \\
\hline \multicolumn{5}{|l|}{ MTR } \\
\hline Group 1 & 10 & $0.22 \pm 0.38$ & $0.32 \pm 0.47$ & 0.10 n.s \\
\hline Group 2 & 6 & $0.11 \pm 0.27$ & $0.19 \pm 0.40$ & 0.18 n.s \\
\hline
\end{tabular}

Wilcoxon signed ranks test, " $p \leq 0.05$; Group 1: Palatal flap compression procedure; Group 2: Primary closure procedure; PD: Probing depth; PT: Palatal thickness; MTR: Marginal tissue recession

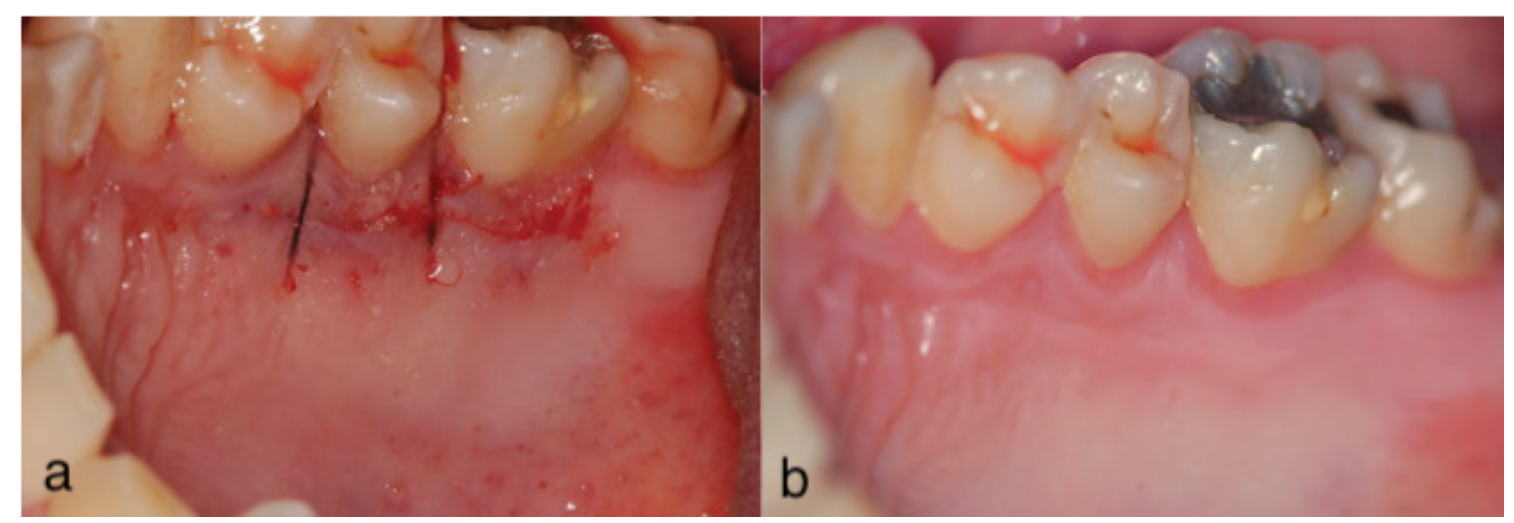

Figure 1: Post-operative view of the primary closure procedure (a) After a CTG removal, a sling suture and cyanoacrylate tissue glue were used to approximate the borders and retain the flap in position; (b) Two weeks later, the area displays a smooth and even tissue layer. 
treatment of mucogingival deformities [10]. Although this region represents the safest area to obtain CTG without causing post-operative complications, one negative side effects is the absence of sufficient tissue to treat multiple tooth recessions ( $>3$ teeth) [7].

Therefore, if the treatment plan includes the use of CTG for the treatment of multiple recessions, a second graft should be harvested from the same donor site, or other options should be evaluated [11].

All procedures used for palatal manipulation are based on hemostasis after CTG removal [12]. The most common and straight forward approach is to compress the flap against the bone, using moist gauze until the bleeding stops. However, this option creates a depression (gap) between the remaining gingival collar and the palatal flap margin, leaving an open wound and, consequently, requiring healing by secondary intention (Figure 2). In contrast, the most desirable goal is to achieve first intention healing by ending the procedure with the edges of the surgical incision close together, which promotes faster cicatrization and better postoperative comfort for the patient (Figure 1) [13].

The results of this study showed that the palatal compression procedure (Group 1) reduced the PT of the area by approximately $0.6 \mathrm{~mm}$, from $2.72 \mathrm{~mm}$ at baseline to $2.12 \mathrm{~mm} 6$ months after the surgery. This decrease in tissue volume might jeopardize the reusability of this area, especially in terms of patient post-operative comfort and predictability. Considering that the epithelial thickness is approximately $0.5 \mathrm{~mm}$ and requires vascularization from connective tissue to survive [14], among cases in which the palatal flap is extremely thin, necrosis, caused by compromised vascularization, is a common finding [15].

In contrast, for the primary closure procedure, the PT of the area was preserved, with no alterations compared with baseline (from $2.92 \mathrm{~mm}$ to $3.06 \mathrm{~mm}$ ). This procedure resulted in better post-operative healing and a predictable prospective treatment plan for the patient.

Based on the results of this study, if a treatment plan includes therapy for multiple tooth recession using a CTG and the same area is required to be used more than once, the first intention healing procedure should be the procedure of choice because it preserves PT relative to the baseline. The loss of thickness, as observed following palatal compression, might compromise the prospective treatment plan and patient postoperative discomfort [16]. The clinical outcomes of this report provide guidance regarding the importance of appropriate palatal donor area manipulations after harvesting a CTG. Further studies, using larger sample sizes, remain necessary to support these conclusions.

\section{Conclusion}

Variations in the palatal manipulation after CTG harvesting may affect the thickness of the donor area for the second harvesting procedure. When possible,

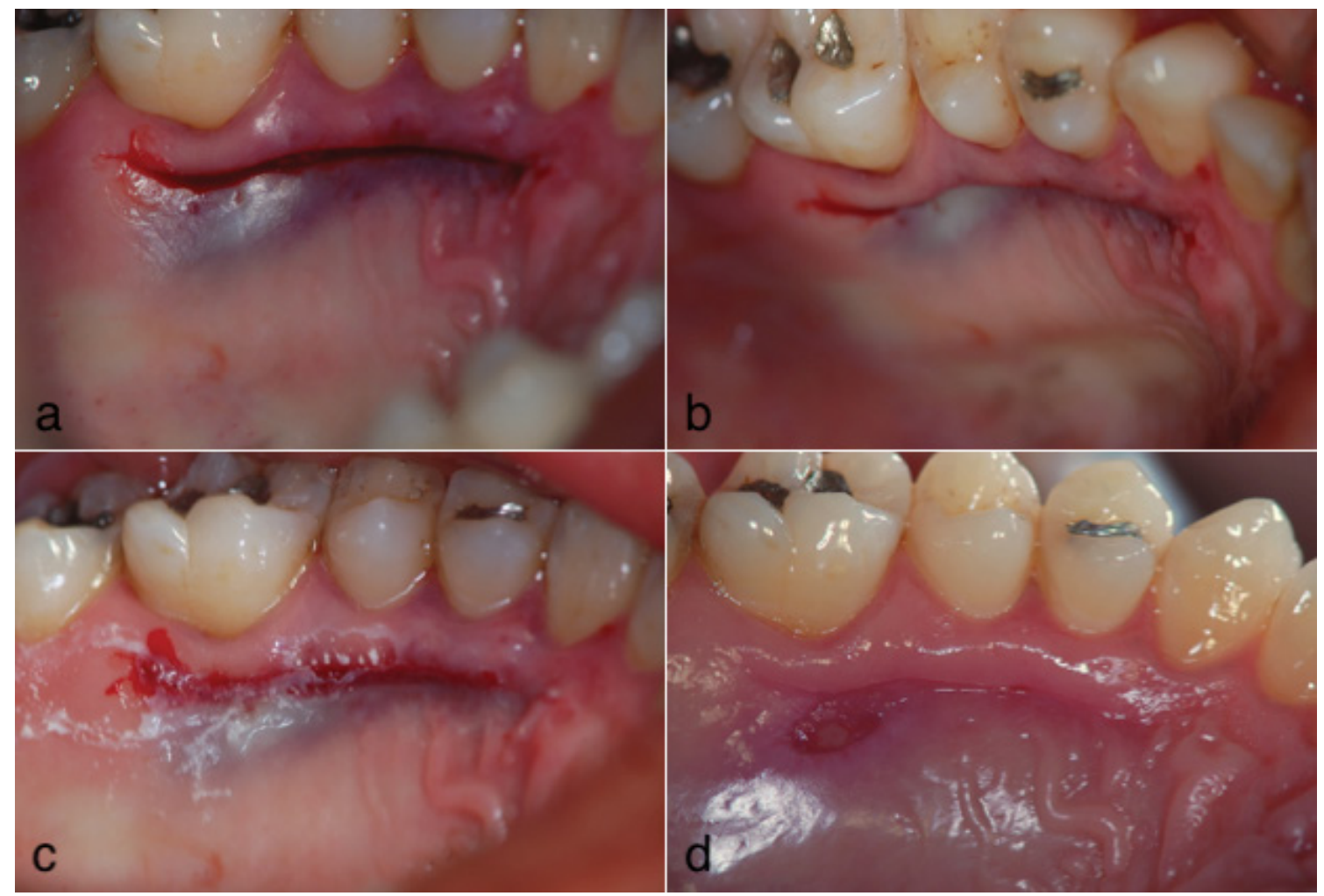

Figure 2: Post-operative view of the palatal flap compression procedure (a) The compression of the flap created a gap between the tissue margins; (b) A clear depression in the area was observed in an occlusal view; (c) The cyanoacrylate tissue glue was used to protect the wound; (d) Two weeks later, an uneven tissue layer remained present. 
the first intention healing should be selected since it preserved the palatal thickness. The compression of the palatal flap to control bleeding may promote a loss of flap density (volume), which may compromise future treatment planning.

\section{Acknowledgments}

The authors report no conflicts of interest related to this study.

\section{References}

1. Langer B, Langer $L$ (1985) Subepithelial connective tissue graft technique for root coverage. J Periodontol 56: 715720.

2. Miller PD Jr (1988) Regenerative and reconstructive periodontal plastic surgery. Mucogingival surgery. Dent Clin North Am 32: 287-306.

3. Takatis DN, Chambrone L, Allen EP, Langer B, McGuire MK, et al. (2015) Periodontal soft tissue root coverage procedures: A consensus report from AAP Regeneration Workshop. J Periodontol 86: S52-S55.

4. Chambrone L, Tatakis DN (2015) Periodontal soft tissue root coverage procedures: A systematic review from the AAP Regeneration Workshop. J Periodontol 86: S8-S51.

5. Sclar A (2000) Cosmetic soft-tissue enhancement for dental implants. Alpha Omegan 93: 38-46.

6. Hürzeler MB, Weng D (1999) A single-incision technique to harvest subepithelial connective tissue grafts from the palate. Int J Periodontics Restorative Dent 19: 279-287.
7. Reiser GM, Bruno JF, Mahan PE, Larkin LH (2015) The subepithelial connective tissue graft palatal donor site: Anatomical consideration for surgeons. Int J Periodontics Restorative Dent 16: 130-137.

8. Inglehart MR (2015) Enhancing periodontal health through regenerative approaches: A commentary on the need for patients-reported outcomes. J Periodontol 86: S4-S7.

9. Duke WW (1983) The relation of blood platelets to hemorrhagic disease. JAMA 50: 1201-1209.

10. Studer SP, Allen EP, Rees TC, Kouba A (1997) The thickness of masticatory mucosa in the human hard palate and tuberosity as potential donor sites for ridge augmentation procedures. J Periodontol 68: 145-151.

11. Carnio J, Koutouzis T (2015) Palatal augmentation technique: A predictable method to increase the palatal connective tissue at donor sites-A consecutive case series. Int J Periodontics Restorative Dent 35: 707-713.

12. Rossmann JA, Rees TD (1999) A comparative evaluation of hemostatic agents in the management of soft tissue graft donor site bleeding. J Periodontol 70: 1369-1375.

13. Allen AL (1994) Use of the supraperiosteal envelope in soft tissue grafting for root coverage. I. Rationale and technique. Int J Periodont Rest Dent 14: 217-227.

14. Wennstrom J (1996) Mucogingival therapy. Ann Periodontol 1: 671-701.

15. Schroeder HE (1981) Differentiation of human oral stratified epithelia. Basel: Karger.

16. Burkhardt R, Hammerle CHF, Lang NP (2015) Self-reported pain perception of patients after mucosal graft harvesting in the palatal area. J Clin Periodontol 42: 281-287. 